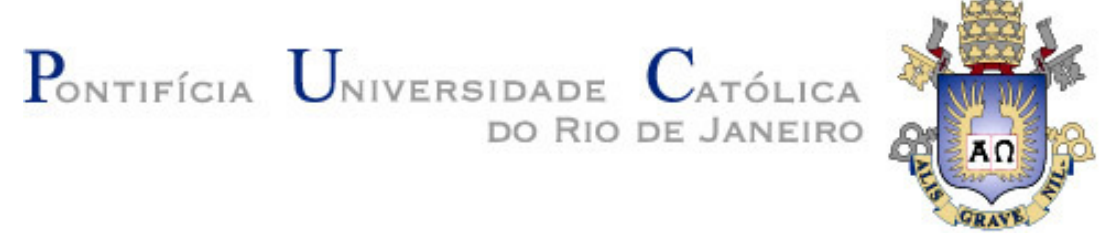

Gabriel Roberto Dellacasa Levrini

\title{
O Estigma dos Consumidores de Baixa Renda no Encontro de Serviços
}

Tese apresentada ao Programa de Pós-Graduação em Administração de Empresas da PUC-Rio, como requisito parcial para obtenção do titulo de Doutor em Administração de Empresas

Orientador: Prof. Paulo Cesar de Mendonca Motta

Rio de Janeiro, outubro de 2012 


\section{Gabriel Roberto Dellacasa Levrini}

\section{O Estigma dos Consumidores de Baixa Renda no Encontro de Serviços}

Tese apresentada como requisito parcial para obtenção do grau de Doutor pelo Programa de Pós-graduação em Administração de Empresas da PUC-Rio. Aprovada pela Comissão Examinadora abaixo assinada.

Prof. Paulo Cesar de Mendonca Motta Orientador

Departamento de Administração - PUC-Rio

Profa. Angela Maria Cavalcanti da Rocha

Departamento de Administração - PUC-Rio

Prof. Luis Fernando Hor-Meyll Alvares Departamento de Administração - PUC-Rio

\section{Profa. Maribel Carvalho Suarez}

UFRJ

Prof. Luís César Souto de Moura

ESPM-RS

Profa. Mônica Herz

Vice-Decana de Pós-Graduação do CCS

Rio de Janeiro, 16 de outubro de 2012 
Todos os direitos reservados. É proibida a reprodução total ou parcial do trabalho sem autorização da universidade, do autor e do orientador.

\section{Gabriel Roberto Dellacasa Levrini}

Graduado em Engenharia Agrônoma na Universidade Federal do Estado do Rio Grande do Sul (RS, Brasil, 1977/1982), especializações em Mercados Futuros pela Bolsa de Mercadorias e USP (SP, Brasil, 1983) e em Corporate Finance, Bankers Trust (New York, USA, 1990), com MBA em Finanças e Economia Internacionais, na Pacific States University, (Los Angeles, USA, 1988/1990), Mestrado em International Trade, na UCLA, (Los Angeles, USA,1990/1992), tem certificação como Conselheiro de Administração pelo Instituto Brasileiro de Governança Corporativa (RS, Brasil, 2010) e em sua trajetória profissional trabalhou como executivo em diversas importantes empresas como: Effem do Brasil, Banco Iochpe S/A, Chase Manhattan Bank, Grupo JOSAPAR, Grupo Eberle Mundial, Tintas Killing S/A., CERAN - Cia. Energética Rio das Antas e na Competence Comunicação e Marketing . Sócio majoritário da empresa El Milagro Consultoria Empresarial Ltda (RS, Brasil, atualmente).

Ficha catalográfica

Levrini, Gabriel Roberto Dellacasa

O estigma dos consumidores de baixa renda no encontro de serviços / Gabriel Roberto Dellacasa Levrini ; orientador: Paulo Cesar de Mendonça Motta. -2012 .

146 f. : il. (color.) ; $30 \mathrm{~cm}$

Tese (doutorado)-Pontifícia Universidade Católica do Rio de Janeiro, Departamento de Administração, 2012.

Inclui bibliografia

1. Administração - Teses. 2. Consumidor de baixa renda. 3. Estigma. 4. Discriminação. 5. Encontro de serviços. I. Motta, Paulo Cesar de Mendonça. II. Pontifícia Universidade Católica do Rio de Janeiro. Departamento de Educação. III. Título. 


\section{Agradecimentos}

Achei que seria mais fácil. Pensei... afinal... tenho somente que lembrar as inúmeras pessoas que conviveram comigo e passaram na minha vida nos últimos anos. Muitos me ajudaram diretamente no trabalho, na minha formação, nos desafios que tracei para minha vida. Não posso deixar de reconhecer aos colegas do Doutorado na bela amizade que construímos, aos professores e funcionários da PUC-Rio, nas inúmeras pessoas que me ajudaram no trabalho de campo, dos inúmeros novos amigos que eu fiz. Porém não seria justo, eu simplesmente apenas agradecer. Estes anos provocaram mudanças profundas em mim, principalmente mudanças de visão do mundo. Eu mudei. Com certeza eu sou outro! Ratificando o ditado que algum sábio falou “... que podemos fazer tudo na vida desde que realmente queiramos. Tem que realmente querer um misto de obsessão com determinação e uma infindável busca pela felicidade do saber”.

Por esse saber que muito agradeço e que me foi dado de várias maneiras. Deus a quem agradeço por ter insistido comigo não me deixando cair em desespero nem sair do rumo traçado, a minha mãe Dona Maria, minha irmã Beth e sobrinha Gabriela que na distância me protegeram da forma mais doce: tolerância e apoio inquestionáveis.

Agradecimento infinito a Vanuza, a dona Dalva e a querida Regina que me suportaram por tantos anos, literalmente agüentaram o meu mau humor e constantes queixas; que vivenciaram meus momentos de desespero e sempre estiveram do meu lado, incondicionalmente, o que me faz refletir imensamente sobre o verdadeiro conceito de amor e bondade. A minha querida Verinha, que esteve comigo nos momentos da pesquisa e nas dificuldades de penetrar neste novo universo para mim, com sua espiritualidade e amor suportou momentos complicados na minha vida, em que o sofrimento parecia ser o vencedor.

Agradecimento especial ao meu orientador, Dr. Paulo Cesar Motta, não somente pelo conhecimento intelectual que generosamente me doou, mas pelas inúmeras reflexões sobre a vida, sobre as pessoas que vivem em desvantagem no nosso mundo, que passaram a ser meu novo mundo. A todos meus amigos que fazem parte da minha vida, obrigado! 


\section{Resumo}

Levrini, Gabriel Roberto Dellacasa; Motta, Paulo Cesar de Mendonca. O Estigma dos Consumidores de Baixa Renda no Encontro de Serviço. Rio de Janeiro, 2012. 146p. Tese de Doutorado - Departamento de Administração, Pontifícia Universidade Católica do Rio de Janeiro.

Na prestação de serviços, há evidência do estigma e de ações discriminantes que envolvam ações automáticas de preconceito. Diferentes tratamentos aos consumidores podem produzir e experiências problemáticas, com consequências e respostas imediatas nos negócios. Objetivamente, este estudo busca focar mais profundamente o estigma do ponto de vista do consumidor de baixa renda. Analisa os componentes racionais e emocionais das reações desses consumidores perante as interpretações da sociedade. Em parte, busca suprir a lacuna existente na literatura do marketing. A estigmatização de consumidores de baixa renda pode ter forte influência em suas ações e respostas durante o processo de decisão de escolha e compra de serviços. Isso implica num significativo impacto no desempenho dos negócios, ações de anticonsumo contra as marcas. Neste sentido, o encontro de serviços serve como palco para os atores "estigmatizador e estigmatizado", sendo que o consumidor de baixa renda é o protagonista. O estudo foi dividido em três fases: a primeira levantou a preocupação destes consumidores com a estigmatização no encontro de serviços, através de entrevistas experimentais para alinhamento do roteiro. A segunda fase compreendeu uma pesquisa de campo, em que foram utilizadas 210 entrevistas. Para tanto, utilizouse a Técnica do Incidente Crítico. Os dados foram analisados, codificados através do software "OpenLogos". Na terceira fase, realizou-se uma análise do conteúdo das narrativas dos entrevistados, chegando a mais de 1200 palavras, códigos e expressões que identificam as emoções, e mostrou-se como ocorre o perfil do estigma e as reações comportamentais. Os resultados indicaram uma predominância das emoções primárias (medo, vergonha e ofensa, etc) no momento imediato a percepção do estigma pelo consumidor de baixa renda. Posteriormente, inicia-se o processo decorrente (emoções secundárias e terciárias) e suas estratégias de respostas destes consumidores. Dessa forma, ratifico- se a influência e importância do estudo do estigma com suas respectivas implicações as situações de consumo. 


\section{Palavras-chave}

Consumidor de baixa renda; estigma; discriminação; encontro de serviços. 


\section{Abstract}

Levrini, Gabriel Roberto Dellacasa; Motta, Paulo Cesar de Mendonca (Advisor). Low Income Consumers Stigma in Service Encounters. Rio de Janeiro, 2012. 146p. Doctoral Thesis - Departamento de Administração, Pontifícia Universidade Católica do Rio de Janeiro.

This article focuses on low-income consumers facing social stigma in service encounters with contact employees. Stigma is a pervasive aspect of our culture and has been rarely considered in services marketing for low-income consumer. In the past, research didn't pay attention on the low-income consumer's perspective for marketing actions. Recently, attention has turned to examining how people who are targets of negative stereotypes understand and interpret their experience as members of socially devalued groups. The method used in this article comprised three phases. The first phase explored the awareness of stigmatized service encounters by informal interviews with low-income consumers. The second phase consisted in field interviews, the collection data from 210 individuals with confirmation of discriminatory behaviors. The method utilized was the Critical Incident Technique (CIT) using Open Logos Content Analysis software for coding the emotions. The third phase consisted of detail data analysis, searching for words or concepts within texts or sets of texts, and then coded into manageable categories. In this phase, we found more than 1200 words or emotional expressions. Results showed primal emotions (fear, shame, offense) dominance in the stigma perception moment, often followed by secondary and thirdly emotions. In the last step of the process, the coping responses were important in order to understand the consumer attitudes and behaviors as part of this stigma process. The findings assure the importance of studying the stigma process to understand low-income consumer's behaviors.

\section{Keywords}

Low income consumers; stigma; service encounters; discrimination. 


\section{Sumário}

1. Introdução 14

1.1. Contexto 14

1.2. Relevância do Tema 17

1.3. Pergunta de Pesquisa e Objetos 18

1.4. Organização e Princípios que Nortearam a Pesquisa 19

$\begin{array}{ll}\text { 1.5. Delimitação de Pesquisa } & 21\end{array}$

2. Principais Conceitos Críticos Utilizados no Estudo 22

3. Revisão da Literatura $\quad 27$

3.1. O Consumidor Estigmatizado e sua Relação com as Classes Sociais $\quad 28$

3.2. Os Indivíduos e a Construção dos Estigmas 29

3.3. As Relações Interpessoais entre Estigmatizadores e Estigmatizados 32

3.4. Consumidores de Baixa Renda: Problemas e Características 35

3.5. As Emoções e sua Influência no Estigma dos Consumidores 37

3.5.1. Diferenças Conceituais entre Emoções e Sentimentos 39

3.5.2. As Teorias das Emoções 40

3.5.3. As Funções das Emoções 42

3.5.4. Classificações das Emoções: Diferentes Visões 45

3.5.5. As Escalas de Emoções 48

3.5.6. Revisão das Escalas de Emoções 49

3.6. Comportamento do Consumidor e Emoções no Marketing 56

3.6.1. Reações Comportamentais e as Emoções 62

3.7. Resumo, Implicações e Conclusões Teóricas da Revisão
Literatura 
4. Métodos 66

4.1. A Natureza do Estudo 66

4.2. A Pesquisa Qualitativa 66

4.2.1. A Pesquisa Qualitativa e a Técnica do Incidente Crítico
(CIT)

4.2.2. Métodos e Passos de Pesquisa Utilizando a CIT 69

4.3. A Análise de Conteúdo 71

4.4. A Categorização da Pesquisa (Coding) 74

4.5. População Alvo e Amostragem 80

4.6. Limitações da Pesquisa 82

5. Descrição dos Resultados 84

5.1. Percepção da Discriminação e Estigma Contra os

Consumidores de Baixa Renda $\quad 86$

5.2. Respostas e Reações dos Consumidores de Baixa Renda 95

5.2.1. Tipos de Estratégias e Respostas dos Consumidores de Baixa Renda 96

5.2.2. Respostas e Enfrentamento Contra o Estigma 98

6. Análise dos Resultados 107

6.1. Análise Gráfica dos Dados 107

6.2. Emoções $x$ Gênero 110

6.3. Testes 114

$\begin{array}{ll}\text { 7. Conclusões } & 118\end{array}$

8. Implicações Gerenciais e Estudos Futuros 124

8.1. Implicações Gerenciais 124

8.2. Estudos Futuros $\quad 125$

9. Referências Bibliográficas 128

$\begin{array}{ll}\text { Anexos } & 144\end{array}$

Anexo 1 - Roteiro Básico para as Entrevistas $\quad 144$

Anexo 2 - Resumo das Classificações de Baixa Renda $\quad 145$

Anexo 3 - Check List para Realização de Estudos Utilizando CIT 146 


\section{Lista de figuras}

Figura 1 - Resumo Esquemático da Revisão de Literatura 28

Figura 2 - Etapas na Construção de Preconceitos e

Discriminações 31

Figura 3 - Antecedentes do Estigma 34

Figura 4 - Principais Componentes das Emoções 38

Figura 5 - Duas Vias Paralelas de Tomada de Decisão 43

Figura 6 - Perspectiva de Damásio 44

Figura 7 - Antecedentes do Comportamento $\quad 57$

Figura 8 - Emoções no Processo de Aprendizagem de novas
Experiências

Figura 9 - Processo de Análise de Conteúdo 73

Figura 10 - Evolução do Processo de Estigma no Encontro de
Serviços

Figura 11 - Resumo do Teste Qui-Quadrado para o Gênero Masculino 115

Figura 12 - Resumo do Teste Qui-Quadrado para o Gênero Feminino 115

Figura 13 - Antecedentes da Ofensa $\quad 116$

Figura 14 - Modelo da Influência do Estigma no Encontro de
Serviços 


\section{Lista de gráficos}

Gráfico 1 - Profissões dos entrevistados por grandes grupos 81

Gráfico 2 - Análise comparativa das interpretações dos juízes $\quad 108$

Gráfico 3 - Curva da evolução das emoções e das reações $\quad 110$

Gráfico 4 - Representação gráfica das emoções primárias por gênero

111

Gráfico 5 - Representação gráfica das emoções secundárias $\quad 112$

Gráfico 6 - Representação ilustrativa das emoções terciárias 113

Gráfico 7 - Representação gráfica das Reações

Comportamentais por gênero 


\section{Lista de tabelas}

Tabela 1 - Análise de confiabilidade e consistência no julgamento

107

Tabela 2 - Classificação das emoções por frequência

109

Tabela 3 - Distribuição da amostra por gênero

110

Tabela 4 - Emoções primárias por gênero

111

Tabela 5 - Emoções secundárias por gênero

Tabela 6 - Emoções terciárias por gênero

Tabela 7 - Reações comportamentais por gênero 


\section{Lista de quadros}

Quadro 1 - Resumo das principais teorias das emoções e suas abordagens

Quadro 2 - Escala DES de Emoções e seus Descritores

Quadro 3 - Escala CES - Emoções e Descritores de Consumo

Quadro 4 - Escala Westbrook de emoções

Quadro 5 - Resumo Comparativo das escalas estudadas e da escala de pesquisa

Quadro 6 - Reações comportamentais utilizadas na pesquisa

Quadro 7 - Passos da técnica do incidente crítico

69

Quadro 8 - Fases da análise de conteúdo

Quadro 9 - Codificação da pesquisa

Quadro 10 - Faixa de Renda da Amostra

Quadro 11 - Faixa Etária e Gênero dos Entrevistados

81 